\title{
Treatment of uncomplicated malaria at public health facilities and medicine retailers in south- eastern Nigeria
}

\author{
Lindsay J Mangham ${ }^{1 *}$, Bonnie Cundill ${ }^{2}$, Ogochukwu Ezeoke ${ }^{3}$,Emmanuel Nwala ${ }^{3}$, Benjamin SC Uzochukwu ${ }^{3,4,5}$, \\ Virginia Wiseman ${ }^{1}$ and Obinna Onwujekwe ${ }^{3,5}$
}

\begin{abstract}
Background: At primary care facilities in Nigeria, national treatment guidelines state that malaria should be symptomatically diagnosed and treated with artemisinin-based combination therapy (ACT). Evidence from households and health care providers indicates that many patients do not receive the recommended treatment. This study sought to determine the extent of the problem by collecting data as patients and caregivers leave health facilities, and determine what influences the treatment received.

Methods: A cross-sectional cluster survey of 2,039 respondents exiting public health centres, pharmacies and patent medicine dealers was undertaken in urban and rural settings in Enugu State, south-eastern Nigeria.

Results: Although 79\% of febrile patients received an anti-malarial, only 23\% received an ACT. Many patients (38\%) received sulphadoxine-pyrimethamine (SP). A further $13 \%$ of patients received an artemisinin-derivative as a monotherapy. An estimated 66\% of ACT dispensed was in the correct dose. The odds of a patient receiving an ACT was highly associated with consumer demand (OR: 55.5, $\mathrm{p}<0.001$ ).

Conclusion: Few febrile patients attending public health facilities, pharmacies and patent medicine dealers received an $A C T$, and the use of artemisinin-monotherapy and less effective anti-malarials is concerning. The results emphasize the importance of addressing both demand and supply-side influences on malaria treatment and the need for interventions that target consumer preferences as well as seek to improve health service provision.
\end{abstract}

\section{Background}

Malaria remains a major cause of death and illness in children and adults in tropical settings. An integrated strategy is recommended which ensures access to treatment with effective anti-malarials, while also undertaking preventative measures that target vector control [1]. ACT became the recommended treatment for uncomplicated malaria, as resistance emerged to conventional monotherapies, including sulphadoxine-pyrimethamine (SP), chloroquine and amodiaquine, thereby reducing their therapeutic efficacy. Over the last decade, countries have revised their national malaria treatment policies to adopt ACT as the first-line recommended treatment for

\footnotetext{
* Correspondence: lindsay.mangham@lshtm.ac.uk

'Department of Global Health and Development, London School of Hygiene and Tropical Medicine, London, UK

Full list of author information is available at the end of the article
}

uncomplicated malaria. Although these policies are now well established, there are persistent problems with their implementation.

Evidence from several settings on malaria case management report problems with the choice of treatment, showing that ACT is often underused and many patients continue to receive less effective anti-malarials, such as SP [2-4]. There are also concerns about the availability and use of artemisinin monotherapy, as drug resistance is more likely to develop if artemisinin derivatives are taken without a partner drug [5,6]. Problems with the dispensing of malaria treatment have also been observed, with patients frequently receiving inadequate doses and without advice on how the medicines should be taken [2,7]. Ensuring accuracy of drug dispensing is particularly challenging for pharmacies and other drug retailers which typically stock a multitude of different

\section{Biomed Central}


types of ACT and the accurate dosage depends not only on the patient's age or weight but varies by brand depending on the formulation and composition of the active ingredients $[8,9]$.

In Nigeria, it is estimated that children under five years of age have between two and four episodes of malaria each year, and ensuring prompt access to effective treatment is a key strategy of the Nigerian Federal Ministry of Health [10]. At the level of primary care, the national malaria treatment guidelines state that diagnosis should be based on symptoms using the Integrated Management of Childhood Illnesses (IMCI) classification [10]. Thus, patients presenting with febrile illness at health facilities without diagnostic testing available should be presumptively treated for malaria. ACT became the recommended treatment for uncomplicated malaria in 2005 and at this time new treatment guidelines and training materials were developed [10-12]. The first-line recommended treatment is artemether-lumefantrine (AL), though treatment with artesunate-amodiaquine (ASAQ), artesunate-mefloquine (ASMQ) and dihydroartemisinin-piperaquine (DHAPQ) are also considered acceptable [12]. The policy is also clear that SP is reserved for intermittent preventive treatment in pregnancy, and cases of severe malaria should be treated using quinine injection, artemether injection, or artesunate (either as an injection or suppository); otherwise the use of monotherapies is no longer recommended.

The provision and utilization of malaria treatment in south-eastern Nigeria is well researched, with evidence from household surveys, patient records and from health care providers at a range of health facilities showing that many febrile patients do not receive the recommended anti-malarial [4,13-16]. Much less is known about the quality of care provided at health facilities, and this study explores these concerns directly by collecting data from patients exiting public health facilities and medicine retailers. These types of facilities are the main providers of malaria treatment at the primary care level [14]. This paper describes the characteristics of patients and the health facilities they attend, and their experience of care, including the nature of the consultation, the provision of anti-malarial treatments and the quality of drug dispensing. The paper also investigates whether patient, health worker or facility factors are associated with receiving ACT.

\section{Methods}

\section{Study area}

The study was undertaken in two study sites in Enugu State in south-eastern Nigeria: Enugu urban (comprising of Enugu East, Enugu South and Enugu North local government areas (LGAs)) and Udi LGA. Enugu urban is the largest predominantly urban area in Enugu State, and Udi LGA is rural. Malaria is endemic in Enugu State, and occurs all year round. The people of Enugu are of Igbo ethnicity and speak the Igbo language. The activities of the majority of the population include farming, fishing, wine tapping, and poultry keeping and rearing of domestic animals; the main agriculture season runs from November to February.

ACT was introduced into the study site in 2005 by the State Malaria Control Programme. The implementation package consisted of training health workers on symptomatic diagnosis, change in antimalarial policy and rational prescription of antimalarials and was accompanied by a community awareness campaign.

\section{Study setting}

The study was undertaken at public primary health facilities, private sector pharmacies and patent medicine dealers (PMDs) in Enugu State, south-eastern Nigeria [17]. The term PMD refers to retail outlets that are licensed to sell over the counter pharmaceutical products, though often hold a wider range of stock, and typically have no formal training [18]. Pharmacies and PMDs are a major source of malaria treatment $[14,19]$. These facilities are medicine retailers and do not routinely offer clinical care or diagnostic services. At the primary care level, presumptive treatment of malaria is recommended in febrile patients, as few public facilities offer malaria microscopy or RDTs. Primary health centres are usually staffed by community health officers and community health extension workers and supported by registered nurses and midwives [20].

\section{Study design}

A stratified multistage cluster survey was conducted between July and December 2009. The survey sampling was clustered in 16 randomly selected communities and stratified by type of facility: i) public facilities including primary health centres, dispensaries and health posts, and ii) pharmacies and PMDs. Within each community all public primary health centres were included due to their small number. There are a large number of pharmacies and PMDs, and these were randomly selected with probability proportionate to size assuming that a total of 80 (out of 298) medicine retailers could be visited given the financial resources and time available. All health workers within each facility responsible for prescribing or dispensing medicines were included in the study.

A survey sample of 20 patients per public facility was calculated to estimate the primary outcome, the proportion of febrile patients receiving the recommended treatment for malaria, with a precision of $+/-13 \%$, assuming that the variability (intra-cluster correlation, ICC) in treatment between facilities is 0.3 [21]. For pharmacies 
and PMDs, 14 patients per facility allows the primary outcome to be calculated with a precision of $+/-6.6 \%$ assuming the same degree of variation. The estimates assume a prevalence of $50 \%$ for the primary outcome and give the maximum range for precision (if the observed prevalence by higher or lower than $50 \%$ then greater precision would be achieved). The sampling was based on an enumeration of health facilities and their staff conducted in April 2009.

\section{Survey activities}

In advance of the survey a field team visited each facility to explain the purpose of the survey to the head of the facility and obtain informed written consent. Informed consent was reconfirmed verbally on the day of the actual survey. The survey questionnaires were developed specifically for the study and pretested on a non-random sample of individuals with characteristics similar to those of the survey population but not chosen for inclusion in the survey. Survey teams were trained on procedures for conducting the survey and involved in the pretesting and revision of the questionnaires. Site supervisors monitored and supervised all aspects of data collection.

Data were collected using three structured approaches; a patient exit questionnaire, a health worker survey and a health facility audit. Written consent from patients and caregivers (who may or may not be accompanied by the patient) exiting the health facility was sought before screening to determine their eligibility to participate in the survey. An individual was considered eligible if $s /$ he reported seeking treatment for a fever or if s/he had received an ACT. Treatment may be sought for themselves, a child or another person who is not present (the latter applies only at medicine retailers). Individuals that were exiting a health facility were assessed in turn until the patient quota was reached. All workers that were involved in prescribing or dispensing malaria treatment and were available at the time of the survey were invited to complete the health worker survey and written consent was obtained from all participants.

The patient exit questionnaire collected data on the patient's prior treatment seeking and use of anti-malarials, reasons for attendance, the consultation and diagnosis, prescriptions and medicines received, the cost of treatment seeking and the demographic characteristics of the patient. The health worker questionnaire captured data on their characteristics, access to in-service training and national malaria treatment guidelines, malaria knowledge and treatment practices. The health worker survey was conducted once all the patient exit questionnaires had been completed to ensure that the treatment received by patients was not influenced by the content of the health worker questionnaire and the patient exit data best reflects current prescribing practices. The health facility audit was conducted following the health worker survey and collected data on the characteristics of the health facility, diagnostic services, management and procurement of medicine, including the availability of ACT.

\section{Definitions}

The treatment received by patients was assessed against the national malaria treatment guidelines, which recommends that patients with a fever are presumptively treated with an ACT, with the exception of pregnant women in the first trimester. The accuracy of the ACT dose provided to patients was assessed in accordance with dosage recommendations based on the patient's age and the type and composition of ACT received. Thus, the analysis takes into account that the correct number of tablets (or powder sachets) varies by brand, the amount of active ingredients contained in each tablet and whether they are co-formulated or co-blistered. Suspensions were excluded from the analysis on dosing. As patient age was used as a proxy for weight $[11,22]$ this may cause some error in estimating the accuracy of dosing among children, though this would not apply to adults. Patient knowledge on the dose regimen was ascertained by asking the patient or their caregiver to explain how and when the medicine should be taken. Knowledge was considered accurate if they reported the number of tablets (or powder sachets) which should be taken per day over 3 days that corresponds to the specific brand of ACT received, and the patient's age. Suspensions were excluded from the analysis due to the difficulties in accessing the accuracy of the correct dose.

\section{Statistical analysis}

Data were entered and verified using Microsoft Access 2007 (Microsoft Inc., Redmond, Washington) and analysed using STATA version 11.0 (STATA Corporation, College Station, Texas) that allows for complex survey design by identifying different probabilities of selection (sampling weights), clustering and stratification (applying the prefix svy) [23]. Thus, all percentages and odds ratios reported are population-average estimates which have been adjusted to take into account the stratification, clustering and sampling weights of the study design. The weights are equal to the inverse probability of being sampled and took into account the sampling probabilities at the facility, health worker and patient level. At the patient level, number of days it took to recruit patients was used to create a proxy for the volume of patients, with the less time indicative of a larger facility.

Treatment outcomes by strata were compared using the Rao and Scott chi-square correction [24]. Survey logistic regression was used to assess factors associated 
with receiving the recommended treatment. The following were investigated for their potential association: characteristics of the patient and health worker, patient consultation, and the resources available at the health facility (all factors are listed in Table six). Factors associated with receiving the recommended treatment were investigated in the multivariable model if the univariable association was statistically significant at the 10 percent level, or the odds ratio was less than 0.5 or greater than 1.5. Factors were retained in this multivariable model if they remained significantly associated at the $10 \%$ level of significance or with an adjusted odds ratio less than 0.5 or greater than 1.5. Models were compared using an adjusted Wald test. Pregnant women and children under the age of 6 months were excluded from the analysis because the national malaria treatment guidelines have alternative recommendations for these groups.

\section{Ethical approval}

Ethical approval for this study was obtained from the ethics committees of University of Nigeria and London School of Hygiene and Tropical Medicine.

\section{Results}

Patient characteristics

Data were collected from 100 health facilities and the analysis is based on exit data collected from 1,642 febrile patients attending public facilities and medicine retailers and 149 health workers (Figure 1). There was notable variation in the characteristics of patients attending the different types of health facility (Table 1). More than half $(57 \%)$ of the patients treated at public health facilities were children, while $80 \%$ of the cases presenting at pharmacies and PMDs were adults. Treatment-seeking also varied by education levels and socioeconomic status (SES), with respondents surveyed at medicine retailers more likely to have tertiary education and be of a higher wealth quintile. At medicine retailers $81 \%$ of patients reported it was the first time that they had sought treatment for this illness episode, and $43 \%$ had sought treatment on the same or day following the onset of symptoms. While at public facilities $61 \%$ of patients at public facilities were seeking treatment for the first time and the time before treatment was much longer, with only $16 \%$ seeking treatment on the same or day

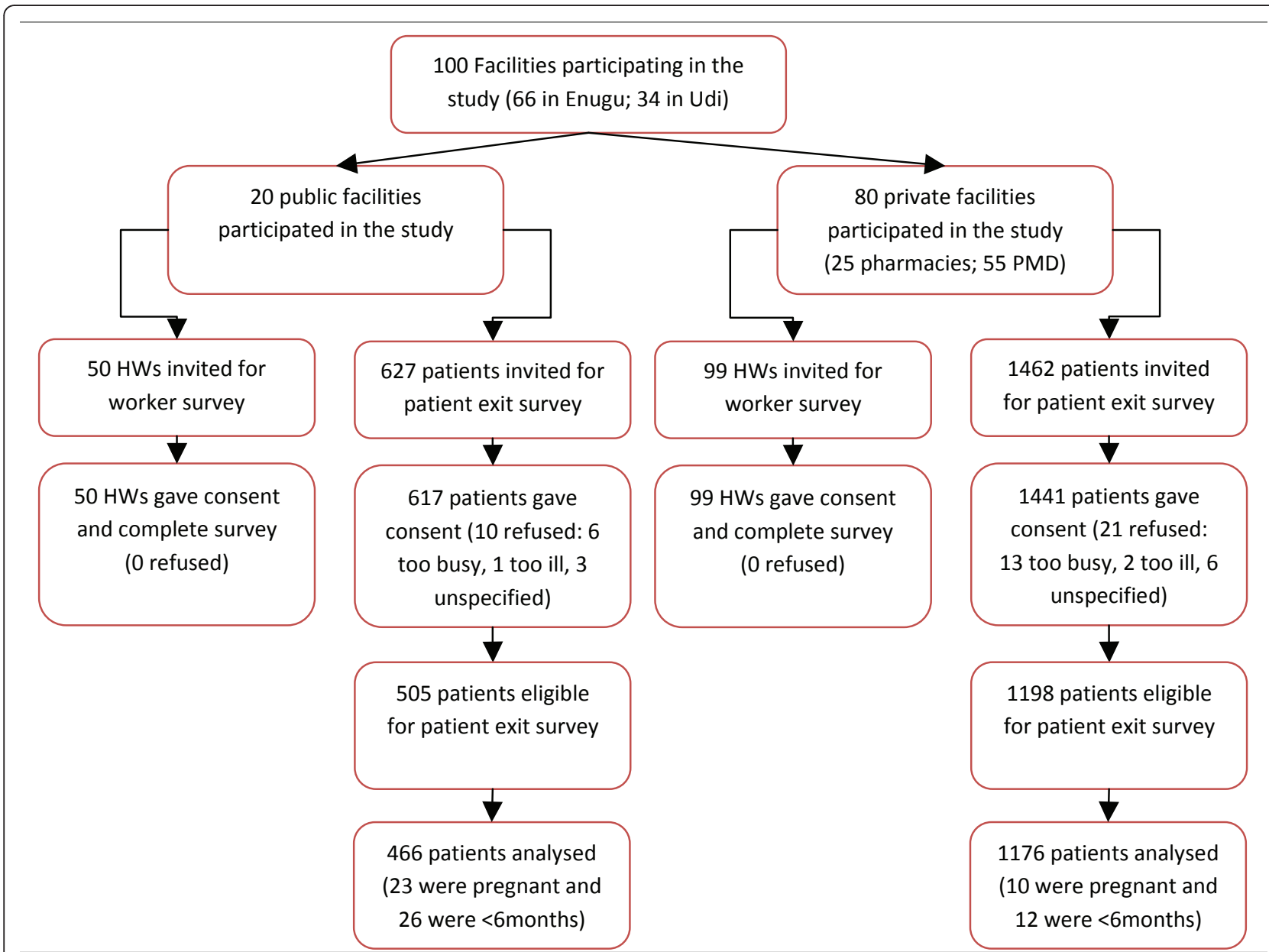

Figure 1 Study population 
Table 1 Patient Characteristics by type of facility*

\begin{tabular}{|c|c|c|c|c|c|c|c|}
\hline & \multicolumn{2}{|c|}{ Public } & \multicolumn{2}{|c|}{ Medicine retailer } & \multicolumn{2}{|c|}{ Total } & \multirow[b]{2}{*}{$P$ value } \\
\hline & $\mathrm{N}=466$ & $\%$ & $N=1176$ & $\%$ & $\mathrm{~N}=1642$ & $\%$ & \\
\hline \multicolumn{8}{|l|}{ Patient gender ${ }^{i}$} \\
\hline Male & 218 & 45.4 & 624 & 56.4 & 842 & 55.5 & 0.006 \\
\hline Female & 242 & 54.6 & 536 & 43.6 & 778 & 44.5 & \\
\hline \multicolumn{8}{|l|}{ Patient age } \\
\hline$>15$ years (adult) & 185 & 42.8 & 913 & 79.6 & 1098 & 76.7 & $<0.001$ \\
\hline $10-15$ years & 27 & 6.6 & 85 & 7.3 & 112 & 7.3 & \\
\hline 5-9 years & 61 & 12.6 & 71 & 4.6 & 132 & 5.3 & \\
\hline$<5$ years & 193 & 38.0 & 107 & 8.4 & 300 & 10.7 & \\
\hline \multicolumn{8}{|c|}{ Patient socioeconomic statusi } \\
\hline Poorest quintile & 223 & 46.4 & 343 & 15.7 & 566 & 18.1 & $<0.001$ \\
\hline Second quintile & 97 & 20.4 & 219 & 20.0 & 316 & 20.1 & \\
\hline Third quintile & 55 & 11.8 & 219 & 21.3 & 274 & 20.6 & \\
\hline Fourth quintile & 56 & 13.5 & 189 & 21.2 & 245 & 20.6 & \\
\hline Richest quintile & 35 & 8.0 & 206 & 21.8 & 241 & 20.7 & \\
\hline \multicolumn{8}{|c|}{ Education level of patient (or caregiver) (ii $^{\mathrm{ii}}$} \\
\hline No formal education & 25 & 5.8 & 41 & 1.3 & 66 & 1.6 & $<0.001$ \\
\hline Primary education & 116 & 28.0 & 198 & 12.5 & 314 & 13.7 & \\
\hline Secondary education & 213 & 46.1 & 469 & 39.7 & 682 & 40.2 & \\
\hline Tertiary education & 93 & 20.0 & 445 & 46.6 & 538 & 44.5 & \\
\hline \multicolumn{8}{|c|}{ Was first time sought treatment $^{\text {iv }}$} \\
\hline Yes & 269 & 61.4 & 896 & 81.7 & 1165 & 81.1 & $<0.001$ \\
\hline No & 196 & 38.7 & 273 & 18.3 & 469 & 19.9 & \\
\hline \multicolumn{8}{|c|}{ Number of days since start of symptoms ${ }^{v}$} \\
\hline None (same day) & 14 & 3.3 & 234 & 22.1 & 248 & 20.6 & $<0.001$ \\
\hline 1 day & 71 & 12.6 & 259 & 21.2 & 330 & 20.5 & \\
\hline 2 days & 93 & 19.3 & 228 & 21.2 & 321 & 21.1 & \\
\hline 3-5 days & 202 & 45.4 & 284 & 23.5 & 486 & 25.3 & \\
\hline $6+$ days & 85 & 19.4 & 169 & 12.0 & 254 & 12.6 & \\
\hline \multicolumn{8}{|c|}{ Reasons given for choice of health facility ${ }^{\text {vi }}$} \\
\hline Convenient & 229 & 49.2 & 617 & 55.9 & 846 & 55.4 & 0.284 \\
\hline Used previously & 243 & 48.6 & 732 & 54.7 & 975 & 54.2 & 0.346 \\
\hline Good reputation & 145 & 30.1 & 529 & 49.6 & 674 & 48.1 & 0.002 \\
\hline Availability of drugs & 127 & 23.3 & 548 & 48.7 & 675 & 46.7 & 0.001 \\
\hline Inexpensive & 206 & 46.2 & 178 & 13.3 & 384 & 15.9 & $<0.001$ \\
\hline Qualification of staff & 132 & 24.7 & 174 & 12.9 & 306 & 13.9 & 0.011 \\
\hline
\end{tabular}

i missing 22 responses: 6 from public and 16 from medicine retailer

ii Principal components analysis was undertaken to generate a SES index based on household asset ownership [33]. The SES index was disaggregated into wealth quintiles.

iii missing 42 responses: 19 from public and 23 from medicine retailer

iv missing 8 responses: 1 from public and 7 from medicine retailer

$v$ missing 3 responses: 1 from public and 2 from medicine retailer

vi more than one reason could be given

following the onset of symptoms. When asked about their choice of health facility, many respondents said that they had sought treatment at this facility for past illnesses (54\%) and it was convenient (55\%). In addition, patients at public health facilities often mentioned the lower cost of treatment, while the reputation of the provider and the availability of drugs were more often cited at medicine retailers. 
Health facility and health worker characteristics

The provision of basic equipment, such as weighing scales and thermometers was good in public health facilities, though more mixed in pharmacies and PMDs (Table 2). Very few health facilities offered malaria microscopy testing and none of the health facilities surveyed used RDTs. At the time of the survey, all health facilities reported that they had anti-malarials in stock, and field staff verified that ACT was in stock in $80 \%$ of health facilities. There was some variation by facility type, with $71 \%$ of public health centres and $89 \%$ of pharmacies and PMDs stocking at least one ACT. Twothirds of health facilities had artemether-lumefantrine (AL) available, though other types of ACT were common in medicine retailers. Artemisinin monotherapy was available in $96 \%$ of medicine retailers while the vast majority (90\%) of facilities also had SP as well as other types of anti-malarials available; these included less

Table 2 Facility Characteristics

\begin{tabular}{|c|c|c|c|c|c|c|c|}
\hline \multirow[b]{2}{*}{ HEALTH FACILITIES } & \multicolumn{2}{|c|}{ Public } & \multicolumn{2}{|c|}{$\begin{array}{l}\text { Medicine } \\
\text { retailer }\end{array}$} & \multicolumn{2}{|c|}{ Total } & \multirow[b]{2}{*}{$P$ value } \\
\hline & $\mathrm{N}=\mathbf{2 0}$ & $\%$ & $\mathrm{~N}=80$ & $\%$ & $N=100$ & $\%$ & \\
\hline \multicolumn{8}{|l|}{ Equipment and services available } \\
\hline Weighing scalet & 19 & 94.1 & 36 & 50.0 & 55 & 53.1 & $<0.001$ \\
\hline Thermometer & 19 & 94.2 & 35 & 46.5 & 54 & 49.8 & $<0.001$ \\
\hline Microscopy servicest & 3 & 12.8 & 0 & - & 3 & 0.9 & $<0.001$ \\
\hline RDT & 0 & - & 0 & - & 0 & - & - \\
\hline \multicolumn{8}{|l|}{ Availability of anti-malarials } \\
\hline Any anti-malarial & 20 & 100.0 & 80 & 100.0 & 100 & 100.0 & - \\
\hline Artesunate monotherapy & 5 & 24.6 & 76 & 96.1 & 81 & 91.1 & $<0.001$ \\
\hline Sulphadoxine Pyrimethamine (SP) † & 18 & 89.8 & 71 & 89.9 & 89 & 89.9 & 0.982 \\
\hline Chloroquine & 14 & 71.1 & 77 & 96.8 & 91 & 95.0 & $<0.001$ \\
\hline Quinine & 4 & 20.3 & 70 & 89.1 & 74 & 84.3 & $<0.001$ \\
\hline Amodiaquine & 3 & 14.4 & 60 & 85.3 & 63 & 80.3 & $<0.001$ \\
\hline Any type of ACT & 14 & 71.1 & 66 & 89.6 & 80 & 88.3 & $<0.001$ \\
\hline Artemether Lumefantrine (AL) & 12 & 65.6 & 64 & 79.6 & 66 & 78.4 & $<0.001$ \\
\hline Artesunate Amodiaquine (ASAQ) & 2 & 8.6 & 57 & 78.8 & 59 & 73.9 & $<0.001$ \\
\hline Artesunate Mefloquine (ASMQ) & 0 & - & 35 & 52.9 & 35 & 49.2 & $<0.001$ \\
\hline Artesunate Sulphadoxine-Pyrimethamine (ASSP) & 0 & - & 18 & 28.4 & 18 & 26.4 & $<0.001$ \\
\hline Dihydroartemisinin-Piperaquine (DHAPQ) & 0 & - & 55 & 78.0 & 55 & 72.6 & $<0.001$ \\
\hline \multicolumn{8}{|l|}{ Median cost of ACT (\& IQ range) } \\
\hline Adult dose of any ACT & \multicolumn{2}{|l|}{-} & \multicolumn{2}{|c|}{$600(350,750)$} & \multicolumn{2}{|c|}{$600(350,750)$} & - \\
\hline Child dose of any ACT & \multicolumn{2}{|c|}{-} & \multicolumn{2}{|c|}{$350(260,600)$} & \multicolumn{2}{|c|}{$350(250,600)$} & - \\
\hline Adult dose of $\mathrm{AL}$ & \multicolumn{2}{|l|}{-} & \multicolumn{2}{|c|}{$750(650,835)$} & \multicolumn{2}{|c|}{$750(650,820)$} & - \\
\hline Child dose of AL & \multicolumn{2}{|c|}{-} & \multicolumn{2}{|c|}{$650(580,750)$} & \multicolumn{2}{|c|}{$650(520,700)$} & - \\
\hline HEALTH WORKERS & $N=50$ & $\%$ & $N=99$ & $\%$ & $N=149$ & $\%$ & $P$ value \\
\hline Doctor & 7 & 14.0 & 0 & & 9 & 1.7 & $<0.001$ \\
\hline Nurse or Midwife & 7 & 14.0 & 7 & 7.3 & 14 & 8.1 & \\
\hline Community Health Officer & 14 & 28.0 & 1 & 1.3 & 15 & 4.5 & \\
\hline Community Health Extension Worker & 22 & 44.0 & 3 & 4.1 & 25 & 8.9 & \\
\hline Pharmacistł & - & & 3 & 3.9 & 3 & 3.4 & \\
\hline PMD or pharmacy attendant $\neq$ & - & & 85 & 83.4 & 85 & 73.5 & \\
\hline HW has attended malaria training in past 3 years & 13 & 24.6 & 31 & 33.0 & 44 & 31.9 & 0.011 \\
\hline HW has access to malaria treatment guidelines & 15 & 30.9 & 4 & 5.2 & 19 & 8.5 & $<0.001$ \\
\hline $\begin{array}{l}\text { HW accurately reported ACTs are the recommended treatment for uncomplicated } \\
\text { malaria }\end{array}$ & 38 & 77.2 & 44 & 62.2 & 82 & 65.4 & $<0.001$ \\
\hline
\end{tabular}


effective conventional treatments such as chloroquine and amodiaquine.

All the public facilities reported that ACT was available to patients free of charge. In pharmacies and PMDs the median price of an ACT was 600 Naira for an adult dose and 350 Naira for a child dose (which is approximately equivalent to USD $\$ 4.00$ and USD $\$ 2.30$ ). The median price of AL was higher at 750 Naira for an adult dose and 650 Naira for a child dose (equivalent to USD $\$ 6.00$ and USD \$4.30).

Just under half (44\%) of workers in public facilities were community health extension workers, semi-skilled health workers trained in primary care, and while junior to the other cadres listed in Table 2 may prescribe treatment or undertake minor procedures [20]. In the medicine retailers the majority (83\%) described themselves as patent medicine dealers or pharmacy attendants.

Knowledge of malaria treatment was variable, though better in public facilities, as $80 \%$ of workers in public facilities reported that ACT is the recommended treatment for uncomplicated malaria, compared to $62 \%$ of workers in pharmacies and PMDs. Moreover, less than one in three health workers surveyed had attended an in-service malaria training workshop over the past three years and relatively few (9\%) had access to the malaria treatment guidelines (31\% of public health workers and $5 \%$ of health workers at pharmacies and PMDs).

Patient consultation, prescription and requests for medicine The nature of the patient's consultation differed by type of health facility (Table 3). In public health facilities 95\% of respondents reported the health workers were told of the patient's symptoms, and $90 \%$ reported that they had told the health worker about the patient's fever. Patients reported to have been physically examined in $65 \%$ of cases, 50\% had their temperature taken, though just $6 \%$ of patients were tested for malaria. At public facilities with microscopy testing available $21 \%$ of patients were tested for malaria. In pharmacies and PMDs patients were rarely examined $(6 \%)$ or tested $(<1 \%)$, though in $32 \%$ of cases health workers were told about the patient's symptoms and asked further questions.

The majority of patients attending public facilities had medicines prescribed and in $78 \%$ of cases the prescription was for an anti-malarial. ACT was prescribed to $34 \%$ of patients seeking treatment, though as many patients were prescribed SP, which is no longer recommended for treating malaria.

At pharmacies and PMDs, $15 \%$ of patients had a prescription and patients often asked for a specific medicine. At these facilities, $58 \%$ of patients attending asked for an anti-malarial. Patients often asked for SP (26\%), though also requested ACT (16\%) and artemisininmonotherapy (12\%). Almost all (96\%) of those patients that asked for an anti-malarial also received the medicine they had requested.

\section{Malaria treatment received by patients}

Overall, the majority of patients received an anti-malarial, though ACT was received by only $22 \%$ of all patients attending health facilities and by $29 \%$ of children under five years of age (Table 4). SP is no longer recommended, though still frequently used, and $38 \%$ of patients had received this medicine. At public facilities, differences were observed between the proportion of patients that were prescribed and received antimalarials at facilities which had ACT in stock. The proportion of patients that received an antimalarial at public facilities was also low compared to the medicine retailers. There were, however, few differences between the proportions of patients receiving ACT and SP at public health facilities and medicine retailers, though patients were more likely to receive oral artemisinin monotherapy at medicine retailers than public facilities $(14 \%$ compared to $2 \%, \mathrm{p}<0.001)$. Other anti-malarials, such as chloroquine, amodiaquine and quinine were rarely received by patients. By type of ACT, AL (44\%) was most often dispensed and was widely used in the public sector. In medicine retailers, AL was regularly dispensed, though patients also received ASAQ and DHAPQ.

\section{Quality of dispensing of ACT}

Two-thirds (66\%) of all types of ACT dispensed were estimated to be in the correct dose, while $58 \%$ of ACT dispensed were in the correct dose and the patient (or their caregiver) accurately reported how the medicine should be taken (Table 5). Given the challenges in estimating the accuracy of ACT dosage in children, the results are also presented for febrile adults receiving ACT. Overall the results are reasonably similar, with $56 \%$ of ACT received in the correct dose and by patients that had accurate knowledge of how to take the medicine. Very few patients receiving an ACT were told of any side effects associated with the medicine.

\section{Factors influencing treatment received by patients}

The odds of a febrile patient receiving an ACT were significantly associated with whether the patient had a prescription, asked for an ACT, the patient's gender, and the education level of the patient (or their caregiver) (Table 6). Patients were also significantly more likely to receive an ACT at health facilities that were better equipped, and had one or more health workers that knew ACT was recommended for uncomplicated malaria. Patients that chose the health facility because it was convenient or relatively inexpensive were significantly less likely to receive an ACT. Of all the variables considered in the univariable analysis, patients 


\begin{tabular}{|c|c|c|c|c|}
\hline & Public & Medicine retailer & Total & \\
\hline & $N=466$ & $\mathrm{~N}=1176$ & $\mathrm{~N}=1642$ & \\
\hline & $\%(95 \% \mathrm{Cl})$ & $\%(95 \% \mathrm{Cl})$ & $\%(95 \% \mathrm{Cl})$ & $P$ value \\
\hline \multicolumn{5}{|l|}{ Patient reported consultation } \\
\hline Told HW about patient symptoms & $94.9(94.4-95.4)$ & $44.3(36.9-52.0)$ & $48.3(41.3-55.4)$ & $<0.001$ \\
\hline Told HW that had a fever & $89.8(87.2-91.9)$ & $40.3(33.0-48.2)$ & $44.3(37.1-51.4)$ & $<0.001$ \\
\hline HW asked follow up questions about patient's symptoms & $79.9(76.3-83.0)$ & $32.0(25.0-39.9)$ & $35.7(29.1-43.1)$ & $<0.001$ \\
\hline Patient was physically examined & $65.1(48.8-78.5)$ & $6.2(3.5-10.5)$ & $10.8(7.8-14.5)$ & $<0.001$ \\
\hline Patient had temperature taken & $49.7(38.6-60.9)$ & $1.7(0.6-4.9)$ & $5.5(3.9-7.8)$ & $<0.001$ \\
\hline Patient tested for malaria at this facility & $5.8(3.6-9.3)$ & $0.2(0.0-1.4)$ & $0.7(0.3-1.3)$ & $<0.001$ \\
\hline \multicolumn{5}{|l|}{ Patient requests for medicine } \\
\hline \multicolumn{5}{|l|}{$\%$ of patients that asked for: } \\
\hline any type of medicine & $2.8(1.9-4.2)$ & $65.4(57.9-72.3)$ & $60.5(53.7-66.9)$ & $<0.001$ \\
\hline an anti-malarial & $1.2(0.7-2.1)$ & $58.3(51.1-65.2)$ & $53.8(47.3-60.2)$ & $<0.001$ \\
\hline any $\mathrm{ACT}$ & $0.9(0.4-1.9)$ & $16.0(11.1-22.5)$ & $14.8(10.3-20.9)$ & $<0.001$ \\
\hline Artemisinin monotherapy & 0 & $11.5(8.6-15.3)$ & $10.6(8.0-14.1)$ & 0.162 \\
\hline Amodiaquine & 0 & $1.6(0.8-3.4)$ & $1.5(0.7-3.2)$ & 0.402 \\
\hline Chloroquine & $0.1(0.0-0.4)$ & $1.3(0.6-2.7)$ & $1.2(0.6-2.5)$ & $<0.001$ \\
\hline Quinine & 0 & $0.7(0.2-2.6)$ & $0.7(0.2-2.4)$ & 0.631 \\
\hline SP & $0.1(0.1-0.1)$ & $26.2(21.5-31.5)$ & $24.1(19.8-29.1)$ & $<0.001$ \\
\hline \multicolumn{5}{|l|}{ Anti-malarial prescriptions } \\
\hline$\%$ patients prescription (from any facility) & $94.2(92.4-95.6)$ & $15.4(10.7-21.5)$ & $21.6(17.1-26.9)$ & $<0.001$ \\
\hline$\%$ patients that received prescription from this facility & $94.2(92.4-95.6)$ & $1.8(0.7-4.0)$ & $8.8(7.3-11.0)$ & $<0.001$ \\
\hline$\%$ patients that were prescribed*: & & - & - & - \\
\hline an anti-malarial $^{\dagger}$ & $78.4(72.6-83.3)$ & - & - & - \\
\hline any $\mathrm{ACT}^{\ddagger}$ & $34.0(21.9-48.7)$ & - & - & - \\
\hline Artemisinin monotherapy & $4.7(3.1-7.1)$ & - & - & - \\
\hline Amodiaquine & $1.1(0.9-1.5)$ & - & - & - \\
\hline Chloroquine & $3.3(0.8-11.6)$ & - & - & - \\
\hline Quinine & $0.2(0.0-3.1)$ & - & - & - \\
\hline SP & 34.7 (21.7-50.6) & - & - & - \\
\hline
\end{tabular}

* Reported only for public health facilities

† At public facilities $73.4 \%$ of children under five years were prescribed an antimalarial.

\# At public facilities $51.5 \%$ of children under five years were prescribed an ACT. At public health facilities with ACTs in stock $43.8 \%$ of patients (all ages) and $57.9 \%$ of children under five years were prescribed an ACT.

asking for ACT had by far the highest odds ratio of 53.3 (15.9-179.1, $\mathrm{p}<0.001)$. This variable remained highly significant in the multivariable model with an odds ratio of $55.5(15.0-205.6, \mathrm{p}<0.001)$, though the other significant variables were the patient's gender, the education level of the patient (or caregiver), whether the facility had a thermometer available, and whether the facility had health workers that knew ACT was recommended.

\section{Discussion}

There is great need to improve the quality of care for uncomplicated malaria in south-eastern Nigeria. Parasitological diagnosis was available in only $3 \%$ of facilities and while the national malaria treatment guidelines recommend presumptive treatment of a fever with ACT when malaria tests are not available, less than a quarter (22\%) of febrile patients attending facilities received the recommended treatment. Moreover, the estimates show that only $58 \%$ of patients that received ACT were given the correct dose and knew how the medicine should be taken. Inadequate dosing and poor compliance to treatment regimens will reduce the efficacy of the treatment taken and may contribute to the development of drug resistance [25].

After four years with ACT as the recommended firstline antimalarial, these results at public health facilities are extremely concerning. In Kenya and Zambia poor 


\begin{tabular}{|c|c|c|c|c|}
\hline & Public & Medicine retailer & Total & \\
\hline & $\%(95 \% \mathrm{Cl})$ & $\%(95 \% \mathrm{Cl})$ & $\%(95 \% \mathrm{Cl})$ & $P$ value \\
\hline Anti-malarials received (all ages) & $N=466$ & $N=1176$ & $N=1642$ & \\
\hline \multicolumn{5}{|l|}{$\%$ of patients (of all ages) that received: } \\
\hline an anti-malarial & $54.2(44.1-63.9)$ & $81.5(76.2-85.8)$ & $79.3(74.5-83.4)$ & $<0.001$ \\
\hline any ACT† & $17.3(9.0-30.5)$ & $22.8(17.2-29.7)$ & $22.4(17.0-28.8)$ & 0.378 \\
\hline Artemisinin monotherapy* & $2.0(0.8-5.2)$ & $14.4(11.4-18.0)$ & $13.4(10.6-16.7)$ & $<0.001$ \\
\hline Amodiaquine & $0.1(0.00-1.0)$ & $2.0(0.9-4.6)$ & $1.9(0.8-4.2)$ & 0.002 \\
\hline Chloroquine & $2.4(0.5-10.6)$ & $3.3(2.0-5.4)$ & $3.2(2.0-5.2)$ & 0.673 \\
\hline Quinine & 0 & $0.9(0.3-2.2)$ & $0.8(0.3-2.0)$ & 0.501 \\
\hline SP & $33.6(20.9-49.1)$ & $38.2(31.8-45.1)$ & $37.9(31.8-44.3)$ & 0.546 \\
\hline Anti-malarials received (children $<5$ yrs only) & $N=193$ & $N=107$ & $N=300$ & \\
\hline \multicolumn{5}{|l|}{$\%$ of children $<5$ years that received: } \\
\hline an anti-malarial & $33.2(20.0-49.7)$ & $80.2(63.6-90.4)$ & $67.1(53.7-78.1)$ & 0.001 \\
\hline any ACT‡ & $21.3(9.9-39.9)$ & $31.6(18.2-49.0)$ & $28.7(18.0-42.6)$ & 0.329 \\
\hline Artemisinin monotherapy* & $2.0(0.2-14.5)$ & $10.2(3.4-26.8)$ & $7.9(2.9-20.2)$ & 0.110 \\
\hline Amodiaquine & $0.2(0.0-3.0)$ & $9.3(2.3-30.6)$ & $6.7(1.6-23.8)$ & 0.001 \\
\hline Chloroquine & $1.5(0.7-3.2)$ & $12.6(4.2-32.1)$ & $9.5(3.5-23.5)$ & 0.001 \\
\hline Quinine & 0 & $4.5(0.6-26.8)$ & $3.23(0.5-20.2)$ & 0.497 \\
\hline SP & $9.2(3.7-21.0)$ & $19.9(8.5-40.0)$ & $16.9(8.1-32.0)$ & 0.176 \\
\hline Type of ACT received & $N=105$ & $N=210$ & $N=315$ & \\
\hline$\% \mathrm{AL}$ & $96.5(92.5-98.4)$ & $40.2(26.9-55.1)$ & $43.6(31.0-57.2)$ & $<0.001$ \\
\hline$\%$ ASAQ & $3.0(1.4-6.2)$ & $28.5(16.1-45.2)$ & $26.9(15.3-42.8)$ & $<0.001$ \\
\hline$\%$ DHAPQ & 0 & $24.3(15.1-36.5)$ & $22.8(14.3-34.3)$ & 0.074 \\
\hline$\%$ ASMQ & $0.5(0.1-1.9)$ & $4.1(0.9-16.6)$ & $3.9(0.9-15.5)$ & 0.019 \\
\hline$\%$ ASSP & 0 & $2.9(0.7-11.5)$ & $2.8(0.7-10.8)$ & 0.648 \\
\hline
\end{tabular}

quality treatment practices were observed at public and mission facilities soon after ACT was introduced as first-line, though subsequent studies up to five years later show improvements in the proportion of patients that are prescribed and receive ACT $[3,7,26]$. As found elsewhere, the proportion of patients that were prescribed or received an ACT seems low given the availability of ACT at health facilities and the proportion of health workers that knew ACT was recommended $[3,7,27,28]$. It was also interesting to note that only half of patients at public facilities that were prescribed an ACT also received one, though it is not clear why this occurred: $34 \%$ of patients at public facilities were prescribed an ACT, while $17 \%$ received an ACT. The discrepancy is only partially explained by the availability of $\mathrm{ACT}$ and is unlikely to reflect the cost of treatment, as
ACT is provided to patients in public facilities without charge.

There were some problems with the availability of ACT: $70 \%$ of public facilities and $83 \%$ of pharmacies and PMDs had at least one ACT in stock at the time of the survey. While the availability of ACT in the public sector was not as high as has been reported in Angola, Kenya, or Uganda [7,9,28-30], the availability of ACT in the study sites was much higher than the Nigerian national average from 2008, when it was found that $38 \%$ of public health facilities had ACT in stock. The availability of ACT at private sector outlets was found to be higher than the Nigerian national average from 2008, which reported $78 \%$ of pharmacies and $19 \%$ of PMDs had ACT in stock [9]. It is concerning to find that artemisinin monotherapy is widely available in medicine 
Table 5 Quality of dispensing for patients that received an ACT

\begin{tabular}{|c|c|c|c|c|}
\hline & Public & Medicine retailer & Total & \\
\hline & $\%(95 \% \mathrm{Cl})$ & $\%(95 \% \mathrm{Cl})$ & $\%(95 \% \mathrm{Cl})$ & $P$ value \\
\hline All febrile patients that received an $\mathrm{ACT}^{*}$ & $N=100$ & $N=176$ & $N=276$ & \\
\hline$\%$ accurate dose ${ }^{\dagger}$ & $75.8(70.6-80.2)$ & $65.5(50.1-78.1)$ & $66.2(51.8-78.0)$ & 0.135 \\
\hline$\%$ patient has accurate knowledge of treatment regimen ${ }^{\neq i}$ & $68.3(63.7-72.6)$ & $58.5(41.6-73.6)$ & $59.2(43.4-73.3)$ & 0.218 \\
\hline$\%$ patients with accurate dose and knowledge of treatment regimen ${ }^{i i}$ & $66.8(61.3-71.9)$ & $57.2(40.3-72.5)$ & $57.8(41.7-72.4)$ & 0.236 \\
\hline$\%$ patients that reported were told of side effects ${ }^{\text {iii }}$ & $1.5(1.2-1.9)$ & $3.0(0.6-14.0)$ & $3.0(0.6-12.9)$ & 0.357 \\
\hline Febrile adults that received an $\mathrm{ACT}^{*}$ & $N=21$ & $N=125$ & $N=146$ & \\
\hline$\%$ in accurate dose ${ }^{\dagger}$ & $72.8(68.6-76.6)$ & $62.0(43.5-77.5)$ & $62.2(44.2-77.4)$ & 0.165 \\
\hline \% patient has accurate knowledge of treatment regimen ${ }^{\neq i v}$ & $72.8(68.6-76.6)$ & $55.4(36.3-73.0)$ & $55.8(37.1-73.0)$ & 0.051 \\
\hline$\%$ patients with accurate dose and knowledge of treatment regimen ${ }^{\text {iv }}$ & $72.8(68.6-76.6)$ & $55.4(36.3-73.0)$ & $55.8(37.1-73.0)$ & 0.051 \\
\hline$\%$ patients that reported were told of side effects ${ }^{\vee}$ & $6.2(5.0-7.7)$ & $4.2(0.8-18.5)$ & $4.2(0.9-17.8)$ & 0.570 \\
\hline $\begin{array}{l}\text { * excludes suspensions and syrups and limited to cases for which have data } \\
\text { † defined as dose that is consistent guidance on dosage by patient age. } \\
\text { ₹ defined as patient reports treatment regimen is consistent with guidance o } \\
\text { i missing } 10 \text { observations ( } 2 \text { from public and } 8 \text { from medicine retailers) } \\
\text { ii missing } 12 \text { observations ( } 4 \text { from public and } 8 \text { from medicine retailers) } \\
\text { iii missing } 6 \text { observations ( } 2 \text { from public and } 4 \text { from medicine retailers) } \\
\text { iv missing } 2 \text { observations (from medicine retailers) } \\
\text { v missing } 3 \text { observations (from medicine retailers) }\end{array}$ & $\begin{array}{l}\text { osage } \\
\text { sage by patient a }\end{array}$ & & & \\
\hline
\end{tabular}

retailers and that many patients request this medicine. The use of oral artemisinin monotherapy in $13.4 \%$ of patients is also a major concern, since its use without a combination therapy can lead to the development of drug resistance $[5,6]$.

Differences observed between the characteristics of patients by type of health facility are broadly consistent with evidence from household surveys conducted in Nigeria on malaria treatment seeking. For example, rural-urban differences, the education of caregivers, and socioeconomic status have been found to be important determinants of where treatment is sought [14,15,31-33]. Other studies have also shown that urban residents were more likely to obtain $\mathrm{ACT}[15]$ and individuals of higher levels of education and socioeconomic status were more likely to have correct knowledge of malaria treatment [31].

Differences between the facility types in the resources available and the patient's consultation were much as expected, with patients attending public health facilities more likely to discuss symptoms and be examined. Similarly, as pharmacies and PMDs are retail outlets it is not surprising that many lacked weighing scales and thermometers and that patients often asked for specific medicines. Moreover, it was expected that health workers in public facilities would have better access to the malaria treatment guidelines and be more likely to know that ACT is recommended for uncomplicated malaria.
The odds of a febrile patient receiving an ACT were positively associated with the health workers knowledge of the treatment guidelines, though there is no evidence of an association between access to treatment guidelines and attendance at malaria training. It should be noted that these variables were defined at the facility-level because in many cases it was not possible to link patients to the health worker that prescribed or recommended treatment, either because the health worker was absent at the time of the survey or because several health workers attended to the patient.

The treatment received by patients from medicine retailers was often driven by consumer requests for a specific medicine, and the odds of a febrile patient receiving an ACT were extremely high if the patient or their caregiver had asked for one. Previous studies from Nigeria have also highlighted the importance of patient demand. For example, Onwujekwe et al reports that $40 \%$ of providers across a range of primary health facilities said requests by patients influenced the type of drug provided [4]. Qualitative research with patent medicine dealers undertaken by Okeke et al also highlighted that patients often ask for specific medicines and the doses of anti-malarial drugs can be determined by patient's ability to pay [18]. Patients' requests for specific medicine at medicine retailers were likely to include cases for which treatment had been prescribed elsewhere, though as only $15 \%$ of patients had a prescription other factors are likely to be relevant and there 
Table 6 Factors influencing whether a patient received an ACT

\begin{tabular}{|c|c|c|c|c|c|c|c|c|c|}
\hline \multirow[t]{2}{*}{ Variable } & & \multirow[b]{2}{*}{$n / N$} & \multirow[b]{2}{*}{$\%$} & \multicolumn{3}{|c|}{ Univariable Analysis } & \multicolumn{3}{|c|}{ Multivariable Analysis } \\
\hline & & & & OR & $95 \% \mathrm{Cl}$ & $P$ value & OR & $95 \% \mathrm{Cl}$ & $P$ value \\
\hline \multirow[t]{2}{*}{ Study Site } & Enugu & $211 / 989$ & 22.7 & 1.71 & $(0.81-3.61)$ & 0.148 & & & \\
\hline & Udi & $71 / 531$ & 14.7 & 1.0 & & & & & \\
\hline \multicolumn{10}{|l|}{ Patient characteristics } \\
\hline \multirow[t]{2}{*}{ Gender } & Male & $173 / 795$ & 25.3 & 1.63 & $(1.00-2.65)$ & 0.051 & 1.91 & $(1.02-3.55)$ & 0.045 \\
\hline & Female & 109/725 & 17.2 & 1.0 & & & 1.0 & & \\
\hline \multirow[t]{4}{*}{ Age Group } & $>15 \mathrm{yrs}$ & $157 / 1023$ & 19.8 & 1.0 & & 0.336 & & & \\
\hline & $10-15$ yrs & $16 / 104$ & 20.7 & 1.06 & $(0.44-2.53)$ & & & & \\
\hline & $5-9$ yrs & $38 / 124$ & 37.8 & 2.46 & $(0.90-6.74)$ & & & & \\
\hline & $<5 \mathrm{yrs}$ & $71 / 269$ & 29.0 & 1.65 & $(0.88-3.09)$ & & & & \\
\hline \multirow[t]{5}{*}{ Quintile } & Richest & $57 / 230$ & 28.8 & 2.35 & $(1.12-4.96)$ & 0.201 & & & \\
\hline & Fourth & $48 / 217$ & 26.2 & 2.07 & $(0.99-4.35)$ & & & & \\
\hline & Third & $48 / 257$ & 18.7 & 1.34 & $(0.58-3.12)$ & & & & \\
\hline & Second & $61 / 297$ & 19.8 & 1.44 & $(0.64-3.25)$ & & & & \\
\hline & Poorest & $68 / 519$ & 14.6 & 1.0 & & & & & \\
\hline \multirow[t]{4}{*}{ Education Level } & No formal & $3 / 61$ & 2.1 & 0.09 & $(0.02-0.31)$ & 0.001 & 0.13 & $(0.03-0.50)$ & 0.045 \\
\hline & Primary & $45 / 297$ & 19.9 & 1.0 & & & 1.0 & & \\
\hline & Secondary & $113 / 651$ & 19.1 & 0.95 & $(0.47-1.95)$ & & 0.81 & $(0.35-1.85)$ & \\
\hline & Tertiary & $121 / 511$ & 25.4 & 1.37 & $(0.70-2.70)$ & & 0.84 & $(0.41-1.73)$ & \\
\hline \multirow[t]{2}{*}{ First-time go for treatment } & Yes & $207 / 1091$ & 21.5 & 0.93 & $(0.50-1.73)$ & 0.811 & & & \\
\hline & No & $75 / 429$ & 22.7 & 1.0 & & & & & \\
\hline \multirow[t]{5}{*}{ Time before treatment } & Same day & $30 / 229$ & 15.5 & 1.0 & & 0.368 & & & \\
\hline & 1 day & $58 / 302$ & 17.8 & 1.17 & $(0.49-2.83)$ & & & & \\
\hline & 2 days & $60 / 307$ & 23.0 & 1.62 & $(0.78-3.38)$ & & & & \\
\hline & 3-5 days & $95 / 446$ & 28.0 & 2.11 & $(0.97-4.58)$ & & & & \\
\hline & $6+$ days & $39 / 236$ & 23.4 & 1.66 & $(0.64-4.29)$ & & & & \\
\hline \multicolumn{10}{|c|}{ Consultation with health worker (HW) } \\
\hline \multirow[t]{2}{*}{ HW told of symptoms } & Yes & $170 / 1030$ & 18.0 & 0.65 & $(0.34-1.22)$ & 0.162 & & & \\
\hline & No & $112 / 490$ & 25.4 & 1.0 & & & & & \\
\hline \multirow[t]{2}{*}{ HW is told of patient's fever } & Yes & $165 / 961$ & 19.2 & 0.76 & $(0.41-1.43)$ & 0.373 & & & \\
\hline & No & $117 / 559$ & 23.8 & 1.0 & & & & & \\
\hline \multirow[t]{2}{*}{ HW asks follow up Qs } & Yes & $139 / 700$ & 23.6 & 1.33 & $(0.68-2.61)$ & 0.376 & & & \\
\hline & No & $143 / 819$ & 18.5 & 1.0 & & & & & \\
\hline \multirow[t]{2}{*}{ Patient is examined } & Yes & $83 / 370$ & 19.5 & 0.88 & $(0.42-1.87)$ & 0.724 & & & \\
\hline & No & 199/1150 & 22.0 & 1.0 & & & & & \\
\hline \multirow[t]{2}{*}{ Takes patient temperature } & Yes & $53 / 251$ & 19.1 & 0.90 & $(0.44-1.85)$ & 0.755 & & & \\
\hline & No & $229 / 1269$ & 21.9 & 1.0 & & & & & \\
\hline Patient has a prescription & Yes & $99 / 327$ & 42.1 & 3.51 & $(1.77-6.95)$ & 0.001 & & & \\
\hline & No & 183/1193 & 17.1 & 1.0 & & & & & \\
\hline Asked for ACT & Yes & $114 / 138$ & 86.2 & 53.28 & $(15.9-179.1)$ & $<0.001$ & 55.47 & $(15.0-205.6)$ & $<0.001$ \\
\hline & No & 168/1382 & 10.6 & 1.0 & & & 1.0 & & \\
\hline Health facility characteristi & & & & & & & & & \\
\hline Type of facility & Public & $94 / 430$ & 16.6 & 0.70 & $(0.29-1.67)$ & 0.385 & & & \\
\hline & Retailer & 188/1090 & 22.2 & 1.0 & & & & & \\
\hline Weighing scale available & Yes & $216 / 892$ & 27.2 & 2.13 & $(1.05-4.32)$ & 0.037 & & & \\
\hline & No & $66 / 628$ & 14.6 & 1.0 & & & & & \\
\hline Thermometer available & Yes & $198 / 872$ & 27.5 & 1.94 & $(1.01-3.71)$ & 0.046 & 1.99 & $(0.94-4.18)$ & 0.068 \\
\hline & No & $84 / 648$ & 16.2 & 1.0 & & & 1.0 & & \\
\hline Offer malaria microscopy & Yes & $17 / 70$ & 24.0 & 1.12 & $(0.77-1.63)$ & 0.519 & & & \\
\hline
\end{tabular}


Table 6 Factors influencing whether a patient received an ACT (Continued)

\begin{tabular}{|c|c|c|c|c|c|c|c|c|c|}
\hline & No & $265 / 1430$ & 21.7 & 1.0 & & & & & \\
\hline \multicolumn{10}{|c|}{ Facility has one or more HWs that... } \\
\hline \multirow[t]{2}{*}{... have attended malaria training } & Yes & $137 / 660$ & 22.0 & 1.03 & $(0.52-2.02)$ & 0.927 & & & \\
\hline & No & $145 / 860$ & 21.6 & 1.0 & & & & & \\
\hline \multirow[t]{2}{*}{... have access to guidelines } & Yes & $66 / 236$ & 19.2 & 0.83 & $(0.51-1.34)$ & 0.413 & & & \\
\hline & No & $216 / 1284$ & 22.0 & 1.0 & & & & & \\
\hline \multirow[t]{2}{*}{... know ACT is recommended } & Yes & $251 / 1136$ & 24.8 & 2.40 & $(1.03-5.57)$ & 0.043 & 2.47 & $(0.91-6.73)$ & 0.073 \\
\hline & No & $31 / 384$ & 11.5 & 1.0 & & & & & \\
\hline
\end{tabular}

would be merit in further examining the role of patient demand in influencing the choice of treatment for uncomplicated malaria in private sector facilities.

\section{Conclusions}

ACT became the recommended treatment for uncomplicated malaria in 2005, though they remain underused, and less than a quarter of febrile patients attending health facilities in this study received ACT. Although there is increasing emphasis on the parasitological rather than symptomatic diagnosis of malaria, the study suggests that there is a need for interventions that also focus on choice of treatment to ensure that patients with malaria receive the recommended anti-malarial, irrespective of the diagnostic method. Improving the provision of health services should also address the quality of dispensing, and ensure that health workers can accurately determine the correct dose across a range of different brands and types of ACT. Concurrently attention needs to be given to the high availability and use of artemisinin monotherapy, as well as the continued use of less effective treatments, particularly SP. Consideration should also be given to the role of patient demand in influencing the treatment received, especially in medicine retailers, since this was found to be a major determinant of whether patients received an ACT. Thus, in developing interventions to improve malaria case management the results demonstrate the importance of addressing both demand and supply-side influences on malaria treatment.

\section{Funding}

The research was supported by the ACT Consortium, which is funded through a grant from the Bill \& Melinda Gates Foundation to the London School of Hygiene and Tropical Medicine.

\section{Author details}

${ }^{1}$ Department of Global Health and Development, London School of Hygiene and Tropical Medicine, London, UK. 'Department of Infectious Disease
Epidemiology, London School of Hygiene and Tropical Medicine, London, UK. ${ }^{3}$ Health Policy Research Group, Department of Pharmacology and Therapeutics, College of Medicine, University of Nigeria (Enugu Campus), Enugu, Nigeria. ${ }^{4}$ Department of Community Medicine, College of Medicine, University of Nigeria (Enugu Campus), Enugu, Nigeria. ${ }^{5}$ Department of Health Administration and Management, College of Medicine, University of Nigeria (Enugu Campus), Enugu, Nigeria.

\section{Authors' contributions}

LM designed the survey, undertook the data analysis and drafted the paper with assistance from BC, WW, BU and OO. BC undertook sampling and provided advice on data analysis. OE and EN supervised the survey activities, with oversight from BU and OO. W and $\mathrm{OO}$ provided guidance throughout the entire process. All authors read and approved the final manuscript.

\section{Competing interests}

The authors declare that they have no competing interests.

Received: 21 February 2011 Accepted: 8 June 2011

Published: 8 June 2011

\section{References}

1. World Health Organization: Guidelines for the Treatment of Malaria. Second edition. Geneva, Switzerland; 2010.

2. Zurovac D, Rowe AK: Quality of treatment for febrile illness among children at outpatient facilities in sub-Saharan Africa. Ann Trop Med Parasitol 2006, 100:283-296.

3. Zurovac D, Ndhlovu M, Sipilannyambe N, Chanda P, Hamer DH, Simon JL, Snow RW: Paediatric malaria case-management with artemetherlumefantrine in Zambia: a repeat cross-sectional study. Malar J 2007, 6:31.

4. Onwujekwe O, Uzochukwu B, Dike N, Uguru N, Nwobi E, Shu E: Malaria treatment perceptions, practices and influences on provider behaviour: comparing hospitals and non-hospitals in south-east Nigeria. Malar J 2009, 8:246.

5. World Health Organization: WHO briefing on malaria treatment guidelines and artemisinin monotherapies Geneva, Switzerland; 2006.

6. Dondorp AM, Nosten F, Yi P, Das D, Tarning J, Lwin KM, Ariey F, Hanpithakpong W, Lee SJ, Ringwald P, Silamut K, Imwong M, Chotivanich K, Lim P, Herdman T, An, Yeung SS, Singhasivanon P, Day NPJ, Lindegardh N, Socheat D, White NJ: Artemisinin resistance in Plasmodium falciparum malaria. NEJM 2009, 361:455-467.

7. Zurovac D, Njogu J, Akhwale W, Hamer DH, Snow RW: Translation of artemether-lumefantrine treatment policy into paediatric clinical practice: an early experience from Kenya. Trop Med Int Health 2008, 13:99-107.

8. Jimmy EO, Achelonu E, Orji S: Antimalarials dispensing by patent medicine dealers in rural settlements in Nigeria. Public Health 2000, 114:282-285.

9. ACT Watch: Outlet Survey Report (Baseline) Federal Republic of Nigeria 12/08. Abuja, Nigeria; 2008.

10. Federal Republic of Nigeria: National Antimalarial Treatment Policy Abuja, Nigeria; 2005. 
11. Federal Republic of Nigeria: National Antimalarial Treatment Policy Abuja Nigeria; 2005.

12. Federal Republic of Nigeria: Training Manual for Management of Malaria in Nigeria Abuja, Nigeria; Federal Ministry of Health, Abuja, Nigeria; 2005.

13. Meremikwu M, Okomo U, Nwachukwu C, Oyo-lta A, Eke-Njoku J, Okebe J, Oyo-lta E, Garner P: Antimalarial drug prescribing practice in private and public health facilities in south-east Nigeria: a descriptive study. Malar $J$ 2007, 6:55.

14. Okeke TA, Okeibunor JC: Rural-urban differences in health-seeking for the treatment of childhood malaria in south-east Nigeria. Health Policy 2010, 95:62-68.

15. Onwujekwe O, Hanson K, Uzochukwu B, Ezeoke O, Eze Soludo, Dike N: Geographic inequities in provision and utilization of malaria treatment services in southeast Nigeria: diagnosis, providers and drugs. Health Policy 2010, 94:144-149.

16. Uzochukwu BSC, Chiegboka LO, Enwereuzo C, Nwosu U, Okorafor D, Onwujekwe O, Uguru NP, Sibeudu FT, Ezeoke OP: Examining appropriate diagnosis and treatment of malaria: availability and use of rapid diagnostic tests and artemisinin-based combination therapy in public and private health facilities in south east Nigeria. BMC Public Health 2010, 10:486.

17. Uzochukwu BSC, Onwujekwe OE, Soludo E, Nkoli E, Uguru NP: The District Health System in Enugu State, Nigeria: An analysis of policy development and implementation. CREHS research report 2009 [http:// www.crehs.Ishtm.ac.uk/publications.html].

18. Okeke TA, Uzochukwu BSC, Okafor HU: An in-depth study of patent medicine sellers' perspectives on malaria in a rural Nigerian community. Malar J 2006, 5:97.

19. Onwujekwe O, Ojukwu J, Uzochuckwu B, Dike N, Ikeme A, Shu E: Where do people from different socio-economic groups receive diagnosis and treatment for presumptive malarial in south-eastern Nigeria? Ann Trop Med Parasitol 2005, 99:473-481.

20. Ordinioha B, Inyenaporo C: Experience with the use of community health extension workers in primary care, in a private rural health care institution in South-South Nigeria. Annals of African Medicine 2010, 9:240-245

21. Bennett S, Woods T, Liyanage WM, Smith DL: A simplified general method for cluster-sample surveys of health in developing countries. World Health Statistics Quarterly 1991, 44:98-106.

22. World Health Organization: Guidelines for the Treatment of Malaria Geneva, Switzerland; 2006.

23. StataCorp: Stata: Release 11. Statistical Software College Station TX StataCorp L.P; 2009.

24. Rao JNK, Scott AJ: The analysis of categorical data from complex sample surveys: chi-squared tests for goodness-of-fit and independence in twoway tables. J Am Statistical Assoc 1981, 76:221-230.

25. Yeung $\mathrm{S}$, White NJ: How do patients use antimalarial drugs? A review of the evidence. Trop Med Int Health 2005, 10:121-138.

26. Juma E, Zurovac D: Changes in health workers' malaria diagnosis and treatment practices in Kenya. Malar J 2010, 10:1.

27. Wasunna B, Zurovac D, Goodman CA, Snow RW: Why don't health workers prescribe $A C T$ ? A qualitative study of factors affecting the prescription of artemether-lumefantrine. Malar J 2008, 7:29.

28. Zurovac D, Tibenaderana JK, Nankabirwa J, Ssekitooleko J, Njogu JN, Rwakimara JB, Meek S, Talisuna A, Snow RW: Malaria case-management under artemether-lumefantrine treatment policy in Uganda. Malar J 2008, 7:181.

29. Kangwana BB, Njogu J, Wasunna B, Kedenge SV, Memusi, Goodman CA, Zurovac D, Snow RW: Malaria drug shortages in Kenya: a major failure to provide effective treatment. Am J Trop Med Hyg 2009, 80:737-738.

30. Rowe AK, Ponce de Leon G, Mihigo J, Carolina A, Santeli FS, Miller NP, VanDunem P: Quality of malaria case-management at outpatient health facilities in Angola. Malar J 2009, 8:275.

31. Dike N, Onwujekwe O, Ojukwu J, Ikeme A, Uzochuckwu B, Shu E: Influence of education and knowledge on perceptions and practices to control malaria in southeast Nigeria. Soc Sci Med 2006, 63:103-106.

32. Wiseman V, Scott A, Conteh L, Stevens W, Milligan P: Determinants of provider choice for malaria treatment: lessons from The Gambia. Soc Sci Med 2008, 67:487-496.

33. Filmer D, Pritchett LH: Estimating wealth effects without expenditure data or tears: an application to educational enrolments in States of India. Demography 2001, 38:115-132. doi:10.1186/1475-2875-10-155

Cite this article as: Mangham et al:: Treatment of uncomplicated malaria at public health facilities and medicine retailers in south-eastern Nigeria. Malaria Journal 2011 10:155.

\section{Submit your next manuscript to BioMed Central and take full advantage of:}

- Convenient online submission

- Thorough peer review

- No space constraints or color figure charges

- Immediate publication on acceptance

- Inclusion in PubMed, CAS, Scopus and Google Scholar

- Research which is freely available for redistribution
C Biomed Central 